\title{
Self-Assembly of Metal-Organic Framework (MOF) Nanoparticle Monolayers and Free-Standing
}

\section{Multilayers}

\author{
Yuji Katayama, ${ }^{1,2}$ Mark Kalaj, ${ }^{1}$ Kyle S. Barcus, ${ }^{1}$ and Seth M. Cohen ${ }^{1 *}$ \\ ${ }^{1}$ Department of Chemistry and Biochemistry, University of California, San Diego, La Jolla, CA \\ ${ }^{2}$ Asahi Kasei Corporation, 2-1 Samejima, Fuji-city, Shizuoka 416-8501, Japan \\ *scohen@ucsd.edu

\section{SUPPORTING INFORMATION}

\section{Table of Contents}

$\begin{array}{ll}\text { Ligand Syntheses } & \text { S2 }\end{array}$

$\begin{array}{ll}\text { MOF Syntheses } & \text { S3 }\end{array}$

$\begin{array}{ll}\text { SAMM Syntheses } & \text { S3 }\end{array}$

$\begin{array}{ll}\text { Characterization } & \text { S9 }\end{array}$

$\begin{array}{ll}\text { Figures and Tables } & \text { S11 }\end{array}$

$\begin{array}{ll}\text { Determination of chain density } & \text { S24 }\end{array}$ 


\section{Ligand Synthesis}

Starting materials were purchased and used from commercially available suppliers (SigmaAldrich, Acros Organics, Matrix Scientific, and others) and used without further purification.
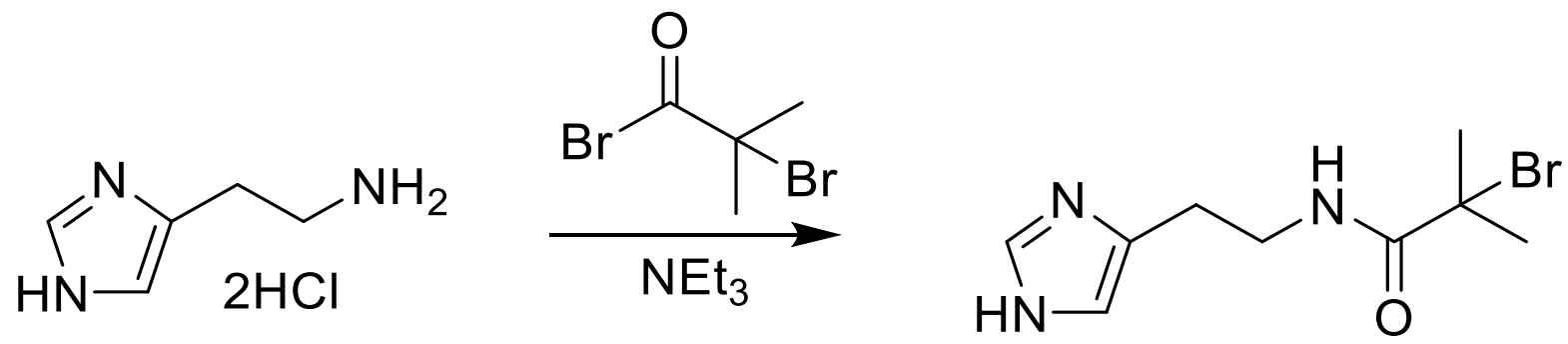

1

Scheme S1. Synthesis of N-(2-(1H-imidazol-4-yl)ethyl)-2-bromo-2-methylpropanamide (hisBiB.

\section{N-(2-(1H-imidazol-4-yl)ethyl)-2-bromo-2-methylpropanamide}

(1).

Histamine dihydrochloride (5.0 g, $27.2 \mathrm{mmol})$, triethylamine (12.7 g, $125.7 \mathrm{mmol}, 4.6 \mathrm{eq})$ and $\mathrm{CHCl}_{3}(400$ $\mathrm{mL}$ ) were added to a $1 \mathrm{~L}$ round bottom flask. The resulting mixture was cooled to $0{ }^{\circ} \mathrm{C}$ in an ice bath, and $\alpha$-bromoisobutyryl bromide (BiBB) $(12.7 \mathrm{~g}, 55 \mathrm{mmol}, 2.0 \mathrm{eq})$ was added dropwise via a syringe. After addition the solution was warmed to room temperature and stirred at room temperature overnight. The reaction was quenched using $500 \mathrm{~mL} 10 \% \mathrm{KOH}$ aqueous solution. The solution was extracted with $\mathrm{CH}_{2} \mathrm{Cl}_{2}$ and dried over magnesium sulfate. After removing solvent, the crude product was recrystallized with EtOAc to give the desired product (compound 1). Yield: $5.6 \mathrm{~g}, 79 \% .{ }^{1} \mathrm{H}$ NMR (400 MHz, $\left.\mathrm{CD}_{3} \mathrm{OD}\right): \delta 7.58(\mathrm{~s}, 1 \mathrm{H}), 6.86(\mathrm{~s}, 1 \mathrm{H}), 3.44(\mathrm{t}, \mathrm{J}=7.2$ $\mathrm{Hz}, 2 \mathrm{H}), 2.80(\mathrm{t}, \mathrm{J}=7.2 \mathrm{~Hz}, 2 \mathrm{H}), 1.88(\mathrm{~s}, 6 \mathrm{H}) . \quad \mathrm{ESI}-\mathrm{MS}(+)$ Experimental: $m / z 260.11[\mathrm{M}+\mathrm{H}]^{+}$, Calculated for $\left[\mathrm{C}_{9} \mathrm{H}_{14} \mathrm{BrN}_{3} \mathrm{O}\right]: 259.03$. 


\section{MOF Syntheses}

ZIF-8. $\mathrm{Zn}\left(\mathrm{CH}_{3} \mathrm{COO}\right)_{2} \bullet 2 \mathrm{H}_{2} \mathrm{O}(1.50 \mathrm{~g}, 6.8 \mathrm{mmol})$ dissolved in $25 \mathrm{~mL}$ water was added to 2methylimidazole $(5.30 \mathrm{~g}, 65 \mathrm{mmol})$ dissolved in $25 \mathrm{~mL}$ of $0.54 \mathrm{mM}$ cetyltrimethylammonium bromide $(\mathrm{CTAB})$ aqueous solution with gentle stirring for $1 \mathrm{~min}$. The mixture turned white after $15 \mathrm{~s}$ and was left undisturbed at room temperature for $2 \mathrm{~h}$. The resulting ZIF-8 particles were collected by centrifugation (fixed-angle rotor, $9000 \mathrm{rpm}, 10 \mathrm{~min}$ ), washed with $3 \times 40 \mathrm{~mL}$ portions of $\mathrm{MeOH}$. In order to prevent the aggregation, the particles were used for the next reaction without drying. The yield was calculated based on the concentration of ZIF-8 solution by taking a small volume of suspension, drying to determine mass, and calculating total mass from total volume. Yield: $1.17 \mathrm{~g}, 75 \%$ based on $\mathrm{Zn}\left(\mathrm{CH}_{3} \mathrm{COO}\right)_{2} \bullet 2 \mathrm{H}_{2} \mathrm{O}$. The crystallinity was confirmed by PXRD to be ZIF-8 (Figure S3), and the particle sizes were determined to be $\sim 174 \pm 15 \mathrm{~nm}$ by SEM imaging (Figure $\mathrm{S} 1)$. The BET surface area $\left(\mathrm{m}^{2} / \mathrm{g}\right)$ was measured as $1625 \pm 55 \mathrm{~m}^{2} / \mathrm{g}$ at $77 \mathrm{~K}$ with $\mathrm{N}_{2}$ on a Micromeritics ASAP 2020 Adsorption Analyzer using volumetric technique (see details below).

ZIF-8-BiB. ZIF-8 (1.12 g, $9.8 \mathrm{mmol})$ was dispersed in $40 \mathrm{~mL}$ of 1-BuOH via solvent exchange of ZIF-8 solution from $\mathrm{MeOH}$ to 1-BuOH by centrifugation (fixed-angle rotor, $9000 \mathrm{rpm}, 10 \mathrm{~min}$ ). The ZIF-8 solution and the his-BiB mixture $(2.55 \mathrm{~g}, 9.8 \mathrm{mmol}, 1.0 \mathrm{eq})$ were added to a $100 \mathrm{~mL}$ round bottom flask. The combined suspension was sonicated for $5 \mathrm{~min}$ in an ultrasonic bath, then stirred at $100{ }^{\circ} \mathrm{C}$ for $4 \mathrm{~h}$. After cooling to room temperature, the particles were collected by centrifugation (fixed-angle rotor, $9000 \mathrm{rpm}, 10 \mathrm{~min}$ ), washed with $3 \times 40 \mathrm{~mL}$ portions of $\mathrm{MeOH}$, and soaked in $\mathrm{MeOH}$ for $24 \mathrm{~h}$. To prevent aggregation, the particles were used for next reaction without drying. Yield: $950 \mathrm{mg}, 85 \%$. The crystallinity was confirmed by PXRD (Figure S3), and the particle shapes and sizes by SEM (Figure S1). The BET surface area $\left(\mathrm{m}^{2} / \mathrm{g}\right)$ was measured to 
be $1557 \pm 158 \mathrm{~m}^{2} / \mathrm{g}$. Conversion of the PSE reaction was confirmed by measuring the digested ZIF8-BiB with ${ }^{1} \mathrm{H}$ NMR $\left(400 \mathrm{MHz}, \mathrm{CDCl}_{3}\right)$. The 2-methylimidazole amount was measured out to be $\sim 2 \mathrm{~mol} \%$.

PSE of ZIF-8 with his-BiB using mild conditions resulted in no evidence of particle degradation. It is important to note this here as previous attempts in the literature to perform postsynthetic chemistry on ZIF-8 particles have resulted in particle degradation (K.C. Jayachandrababu, D.S. Sholl, S. Nair., Structural and Mechanistic Differences in Mixed-Linker Zeolitic Imidazolate Framework Synthesis by Solvent Assisted Linker Exchange and De Novo Routes. J. Am. Chem. Soc. 139, 5906-5915). The ratio of the his-BiB and the quantity of surface imidazole linker was also calculated, indicating that $33 \%$ of the surface was functionalized with his-BiB (see Determination of chain density), which is a reasonable value to consider with PSE mainly occurring on the surface of the particles. In addition, the ATRP initiator density which is equal to density of his- $\mathrm{BiB}$ on the particle surface was also calculated to be 0.45 initiators $/ \mathrm{nm}^{2}$.

ZIF-8-PMMA. ZIF-8-BiB (100 mg, $0.017 \mathrm{mmol}$ initiator) was mixed with $3.6 \mathrm{~mL}$ methanol in a $10 \mathrm{~mL}$ round bottom flask, followed by ultrasonic treatment for $30 \mathrm{~min}$. Then, purified methyl methacrylate (1.3 g, $13.6 \mathrm{mmol}, 800$ eq based on the initiator), $0.9 \mathrm{~mL}$ of $\mathrm{CuCl}_{2}$-PMDETA ( $\mathrm{N}, \mathrm{N}$, N', N', N"'-pentamethyldiethylenetriamine) stock solution (containing $0.0041 \mathrm{mmol} \mathrm{CuCl}_{2}$, $0.041 \mathrm{mmol}$ PMDETA) were added sequentially under magnetic stirring. After that, the vial was sealed with a rubber plug and degassed by $\mathrm{N}_{2}$ purging. After 30 min, a degassed solution of ascorbic acid (17 mg, $0.1 \mathrm{mmol})$ in $1 \mathrm{~mL} \mathrm{MeOH}$ was added via a syringe. The molar ratio of the reagents was monomer: macroinitiator: catalyst: ligand: reducing agent $=800: 1: 0.24: 2.4: 5.6$. The reaction was kept at room temperature for $18 \mathrm{~h}$. The particles were collected by centrifugation 
(fixed-angle rotor, $9000 \mathrm{rpm}, 10 \mathrm{~min}$ ), washed with $3 \times 40 \mathrm{~mL}$ portions of $\mathrm{MeOH}$. The particles were subsequently washed $1 \times 40 \mathrm{~mL}$ of toluene to wash off any excess polymer. The ZIF-8PMMA particles were dried in a vacuum oven at $60^{\circ} \mathrm{C}$ for $24 \mathrm{~h}$. The crystallinity was confirmed by PXRD to be ZIF-8 (Figure S3), and the particle shapes were confirmed by SEM (Figure S1). BET surface area $\left(\mathrm{m}^{2} / \mathrm{g}\right)$ was measured at $77 \mathrm{~K}$ with $\mathrm{N}_{2}$ on a Micromeritics ASAP 2020 Adsorption Analyzer using volumetric technique to be $1398 \pm 80 \mathrm{~m}^{2} / \mathrm{g}$. After digestion, polymer precipitate was confirmed to be PMMA (Figure S4) via ${ }^{1} \mathrm{H}$ NMR (400 MHz, $\left.\mathrm{CDCl}_{3}\right)$. GPC was measured with THF and the results $\left(\mathrm{M}_{\mathrm{w}}=122 \mathrm{k} \mathrm{m} / \mathrm{mol}, \mathrm{M}_{\mathrm{n}}=75 \mathrm{k}, \mathrm{M}_{\mathrm{w}} / \mathrm{M}_{\mathrm{n}}=1.63\right)$ indicate that the polymerization was successful, albeit with poor control (Figure S5). The relatively high dispersity is unsurprising, as ascorbic acid is known to rapidly reduce $\mathrm{Cu}(\mathrm{II})$ to $\mathrm{Cu}(\mathrm{I})$ which lowers the concentration of deactivator and overall control of the polymerization, and the 2bromoisobutyramide initiator can limit the initiation efficiency of MMA due to the penultimate effect (K. Min, H. Gao, K. Matyajaszewki., Use of Ascorbic Acid as Reducing Agent for Synthesis of Well-Defined Polymers by ARGET ATRP. Macromolecules, 2007, 40, 1789-1791 and C. Y. Lin, M. L. Coote, A. Petit, P. Richard, R. Poli, K. Matyjaszewski., Ab Initio Study of the Penultimate Effect for the ATRP Activation Step Using Propylene, Methyl Acrylate, and Methyl Methacrylate Monomers, Macromolecules, 2007, 40, 5985-5994). However, this was not seen as a drawback, as several studies have shown that broad dispersity of the polymer brush can increase particle-particle interaction (J. Midya, Y. Cang, S. A. Egorov, K. Matyjaszewski, M. R. Bockstaller, A. Nikoubashman, G. Fytas., Disentangling the Role of Chain Conformation on the Mechanics of Polymer Tethered Particle Materials, Nano Lett., 2019, 19, 2715-2722 and Z. Wang, J. Yan, T. Liu, Q. Wei, S. Li, M. Olszewski, J. Wu, J. Sobieski, M. Fantin, M. R. Bockstaller, K. 
Matyjaszewski., Control of Dispersity and Grafting Density of Particle Brushes by Variation of ATRP Catalyst Concentration, ACS Macro Lett. 2019, 8, 859-864).

Digestion of ZIF-8-BiB particles. $10.0 \mathrm{mg}$ of dry ZIF-8-BiB particles were immersed in mixture of $480 \mu \mathrm{L}$ of MeOD solution and $20 \mu \mathrm{L}$ of $\mathrm{D}_{2} \mathrm{SO}_{4}$ with bath sonication until the solution becomes clear. The ratio of the integral value of the alkyl group ( $\alpha$-bromoisobutyryl) in his-BiB and the aromatic group of 2-methylimidazole in ZIF-8 was used to determine the conversion with results which showed $1.7 \pm 0.3 \mathrm{~mol} \%$ his-BiB when compared to the total 2-methylimidazole content of the ZIF-8 particles.

Digestion of ZIF-8-PMMA. $20.0 \mathrm{mg}$ of dry ZIF-8-PMMA particles were immersed in $480 \mu \mathrm{L}$ of $\mathrm{MeOH}$ solution and $20 \mu \mathrm{L}$ of $\mathrm{H}_{2} \mathrm{SO}_{4}$ with bath sonication for twenty minutes. Obtained precipitation was collected via centrifugation, washed with $3 \times 10 \mathrm{~mL}$ portions of $\mathrm{MeOH}$, and dried under vacuum at $50{ }^{\circ} \mathrm{C}$.

\section{$\underline{\text { SAMM Film Fabrication }}$}

Monolayer film fabrication (Evaporation-induced interfacial assembly). ZIF-8-PMMA (30 mg) was mixed with $1 \mathrm{~mL}$ toluene in a small vial, followed by ultrasonic treatment for $60 \mathrm{~min}$. The interfacial assembly of ZIF-8-PMMA particles was carried out by dispensing $10 \mu \mathrm{L}$ of ZIF8-PMMA solution onto the water in a 4 inch petri dish. After drying for $1 \mathrm{~min}$, the thin SAMM was scooped with SEM carbon tape or a TEM grid onto the glass plate. 
Fabrication of monolayer on $\mathrm{SiO}_{2}$ microparticles. An aqueous solution of $\mathrm{SiO}_{2}$ microparticles (Aldrich, particle size $5 \mathrm{um}$ ) was placed onto SEM carbon tape placed on a glass slide. This carbon tape was used to collect the SAMM using the same procedure shown above.

Homo-multilayer film fabrication. ZIF-8-PMMA (30 mg) was mixed with $1 \mathrm{~mL}$ toluene in a small vial, followed by ultrasonic treatment for $60 \mathrm{~min}$. For the fabrication of the first layer, the interfacial assembly of SAMM was carried out by dispensing $10 \mu \mathrm{L}$ of ZIF-8-PMMA solution onto the water in petri dish. After drying for $1 \mathrm{~min}$, the thin film was scooped with a thin cover glass. After drying the film at $100{ }^{\circ} \mathrm{C}$ for $10 \mathrm{~min}$, the same procedure was utilized for the fabrication of the second and third layer sequentially. The thin cover glass was broken, and the edge of the multi-layer film was exposed for cross-section SEM.

Hetero-multilayer films fabrication. SAMM was synthesized using the monolayer procedure above. After drying for $1 \mathrm{~min}$, the SAMM was scooped with a thin cover glass and dried at 100 ${ }^{\circ} \mathrm{C}$ for 10 min. PMMA (Aldrich, average $\mathrm{M}_{\mathrm{w}} \sim 120,000$ ) was used for the fabrication of the second layer and the fourth layer. PMMA (4.5 mg) was mixed with $1 \mathrm{~mL}$ toluene in a small vial. The thin PMMA film fabrication was carried out by dispensing $20 \mu \mathrm{L}$ of PMMA solution onto the water in petri dish. After drying for $1 \mathrm{~min}$, the thin film was scooped with the thin cover glass with the first layer and dried at $100{ }^{\circ} \mathrm{C}$ for $10 \mathrm{~min}$. The third layer and the fourth layer were also fabricated with the same procedure sequentially. The thin cover glass was broken, and the edge of the multi-layer film was exposed for the cross-section SEM measurement. 
Self-standing film fabrication. ZIF-8-PMMA (30 mg) was mixed with $1 \mathrm{~mL}$ toluene in a small vial, followed by ultrasonic treatment for $60 \mathrm{~min}$. The interfacial assembly of SAMM was carried out by dispensing $10 \mu \mathrm{L}$ of ZIF-8-PMMA solution onto the water in $20 \mathrm{~mL}$ vial. After drying for $30 \mathrm{~min}$, the film was harvested on a wire ring as a free-standing film, showing opalescence (Figure 3). The obtained film was used for SEM measurement. The particles were stacked as five SAMMs and the film was $1 \mu \mathrm{m}$ thick as evidenced by SEM images (Figure S12). 


\section{Characterization}

Nuclear Magnetic Resonance. Proton nuclear magnetic resonance spectra $\left({ }^{1} \mathrm{H}\right.$ NMR) were recorded on a Varian FT-NMR spectrometer $(400 \mathrm{MHz})$. Chemical shifts are reported in parts per million (ppm) referenced to the appropriate solvent peak.

Powder X-Ray Diffraction (PXRD). $\sim 50 \mathrm{mg}$ of dry MOF powder or $0.5 \mathrm{~cm}^{2}$ or SAMM was mounted on a silicon sample holder for analysis by PXRD. PXRD data was collected at ambient temperature on a Bruker D8 Advance diffractometer at $40 \mathrm{kV}, 40 \mathrm{~mA}$ for $\mathrm{Cu} \mathrm{Ka}(1=1.5418 \AA)$, with a scan speed of $2 \mathrm{sec} / \mathrm{step}$, a step size of $0.05^{\circ}$ in $2 \theta$, and a $2 \theta$ range of $2-50^{\circ}$.

BET Surface Area Analysis. Samples for analysis were evacuated on a vacuum line overnight at room temperature prior to analysis. $\sim 50 \mathrm{mg}$ samples were then transferred to pre-weighed sample tubes and degassed at $105{ }^{\circ} \mathrm{C}$ on a Micromeritics ASAP 2020 Adsorption Analyzer for a minimum of $12 \mathrm{~h}$ or until the outgas rate was $<5 \mathrm{mmHg}$. After degassing, the sample tubes were re-weighed to obtain a consistent mass for the samples. BET surface area $\left(\mathrm{m}^{2} / \mathrm{g}\right)$ measurements were collected at $77 \mathrm{~K}$ with $\mathrm{N}_{2}$ on a Micromeritics ASAP 2020 Adsorption Analyzer using volumetric techniques.

Scanning Electron Microscopy (SEM). MOF particles or MMM films (approx. $3 \mathrm{~mm}^{2}$ ) were transferred to conductive carbon tape on a sample holder disk, and coated using an Ir-sputter coating for $8 \mathrm{sec}$. A FEI Quanta 250 SEM instrument was used for acquiring images using a $5 \mathrm{kV}$ energy source under vacuum at a working distance at $10 \mathrm{~mm}$. Particle sizes of more than 10 different particles were measured in SEM images and given with error bars as a standard deviation. 
Contact angle measurements. Water contact angles were measured using a a Ramé-Hart DROPimage CA v2.5 instrument and the manufacturer's software. Approximately 5-10 mg of the sample was pressed onto a glass slide with another glass plate. A drop of water was slowly dropped onto the sample with a microsyringe and the contact angle was measured (Figure S5). 


\section{Figures and Tables}

a)

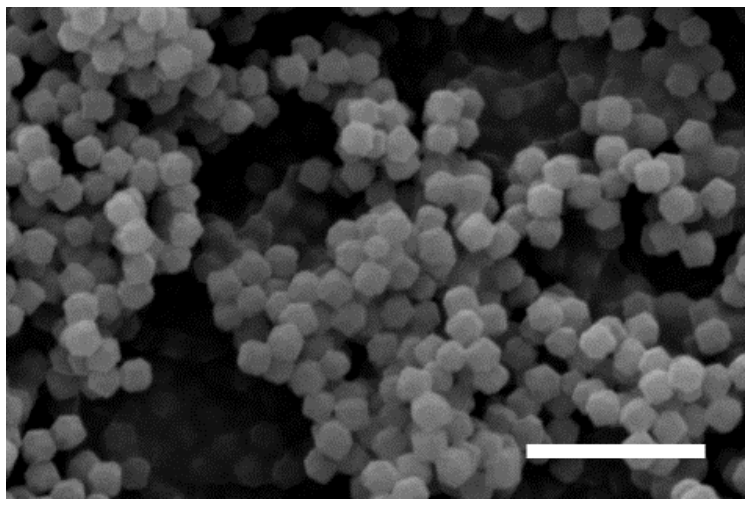

c)

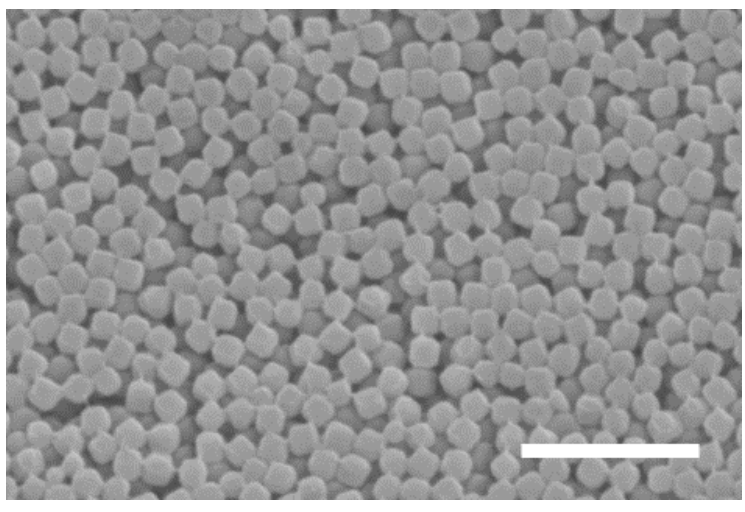

b)
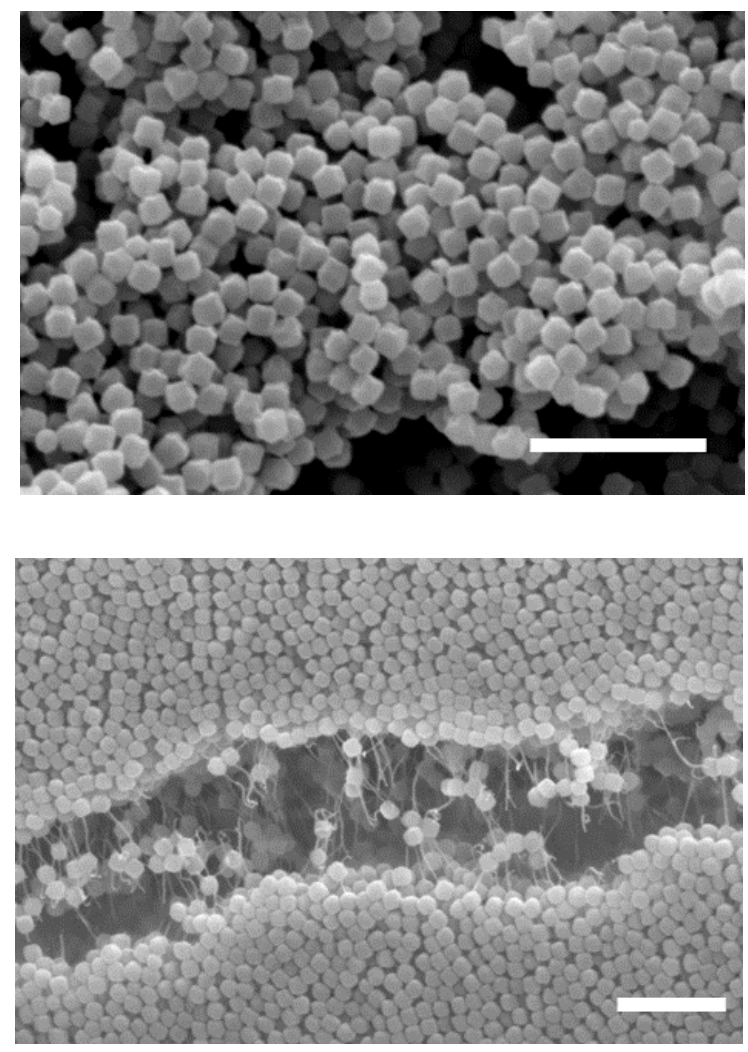

Figure S1. SEM images of MOF particles. a) ZIF-8, b) ZIF-8-BiB, and c) ZIF-8-PMMA d) Crack of ZIF-8-PMMA aggregation. Electron beam of SEM $(5 \mathrm{kV})$ resulted in a cracked area where the existence of PMMA around the MOF particles is evident. Scale bars are $1 \mu \mathrm{m}$. 


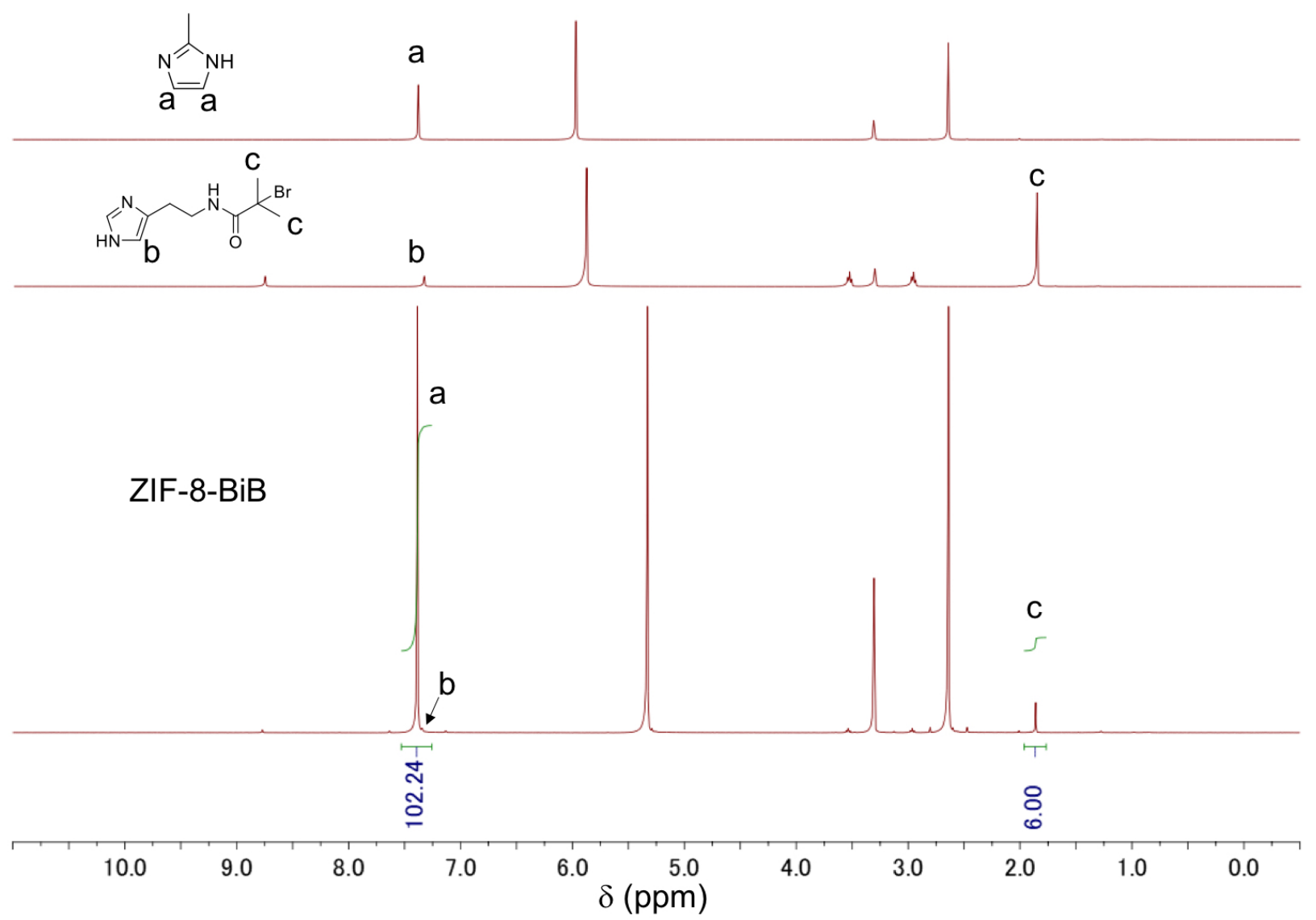

Figure S2. NMR spectra of ZIF-8-BiB after digestion. The conversion of his-BiB in the ZIF-8$\mathrm{BiB}$ was calculated based on the integral value of $1.86 \mathrm{ppm}$ of hydrogen peak of $\alpha$ bromoisobutyryl group in his-BiB and $7.39 \mathrm{ppm}$ of aromatic hydrogen peak of 2-methylimidazole and aromatic hydrogen peak of his-BiB. his-BiB conversion was calculated via the equation: (Integral value of hydrogen peak of $\alpha$-bromoisobutyryl group in his-BiB / 6) / ((Integral value of aromatic hydrogen peaks - Integral value of hydrogen peak of $\alpha$-bromoisobutyryl group in his$\mathrm{BiB} / 6) / 2+($ Integral value of hydrogen peak of $\alpha$-bromoisobutyryl group in his-BiB / 6) $) \times 100$. 


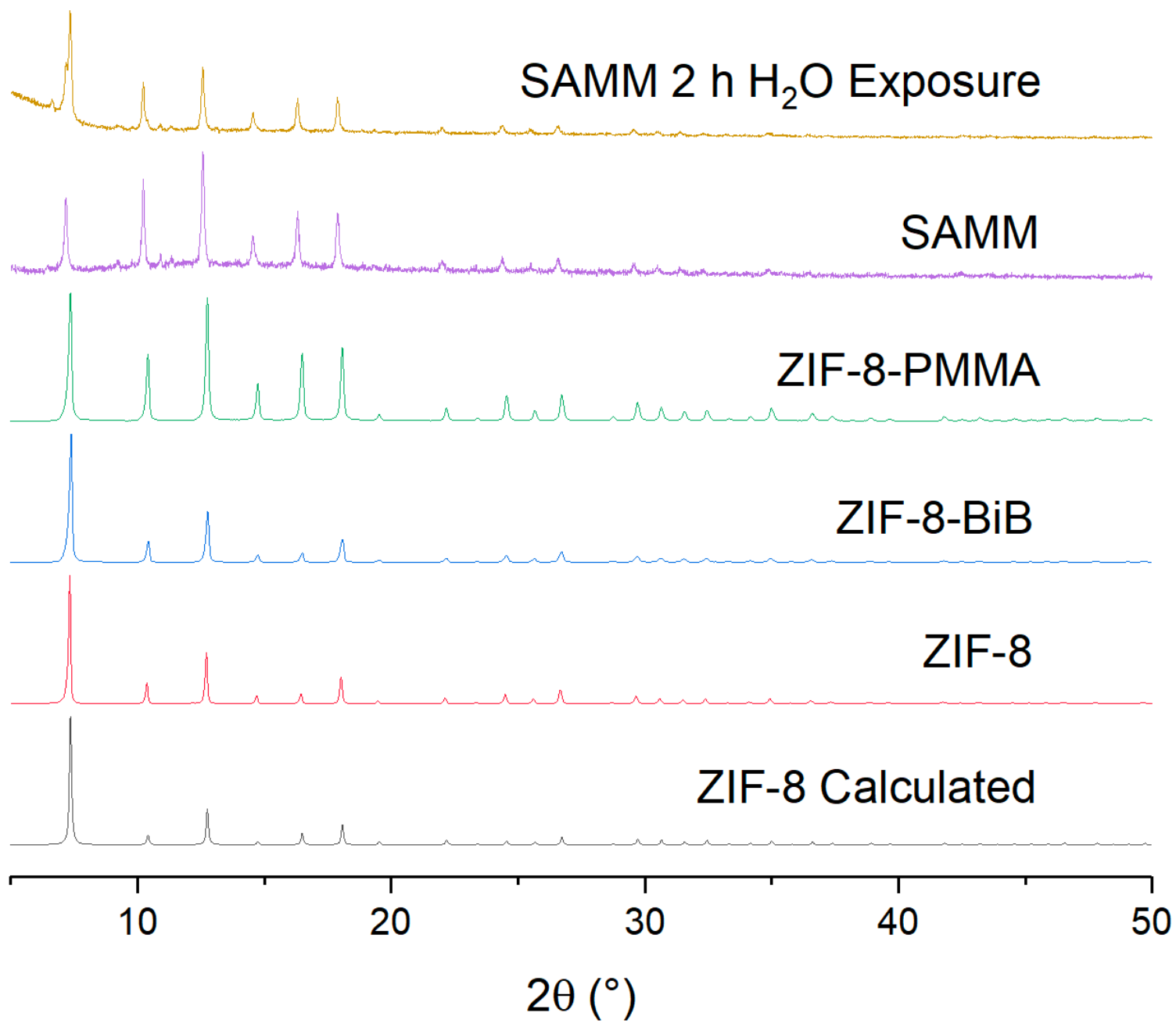

Figure S3. PXRD spectra of ZIF-8 (simulated pattern), ZIF-8, ZIF-8-BiB, ZIF-8-PMMA SAMM, and ZIF-8-PMMA SAMM after exposure to $\mathrm{H}_{2} \mathrm{O}$ for $2 \mathrm{~h}$. 


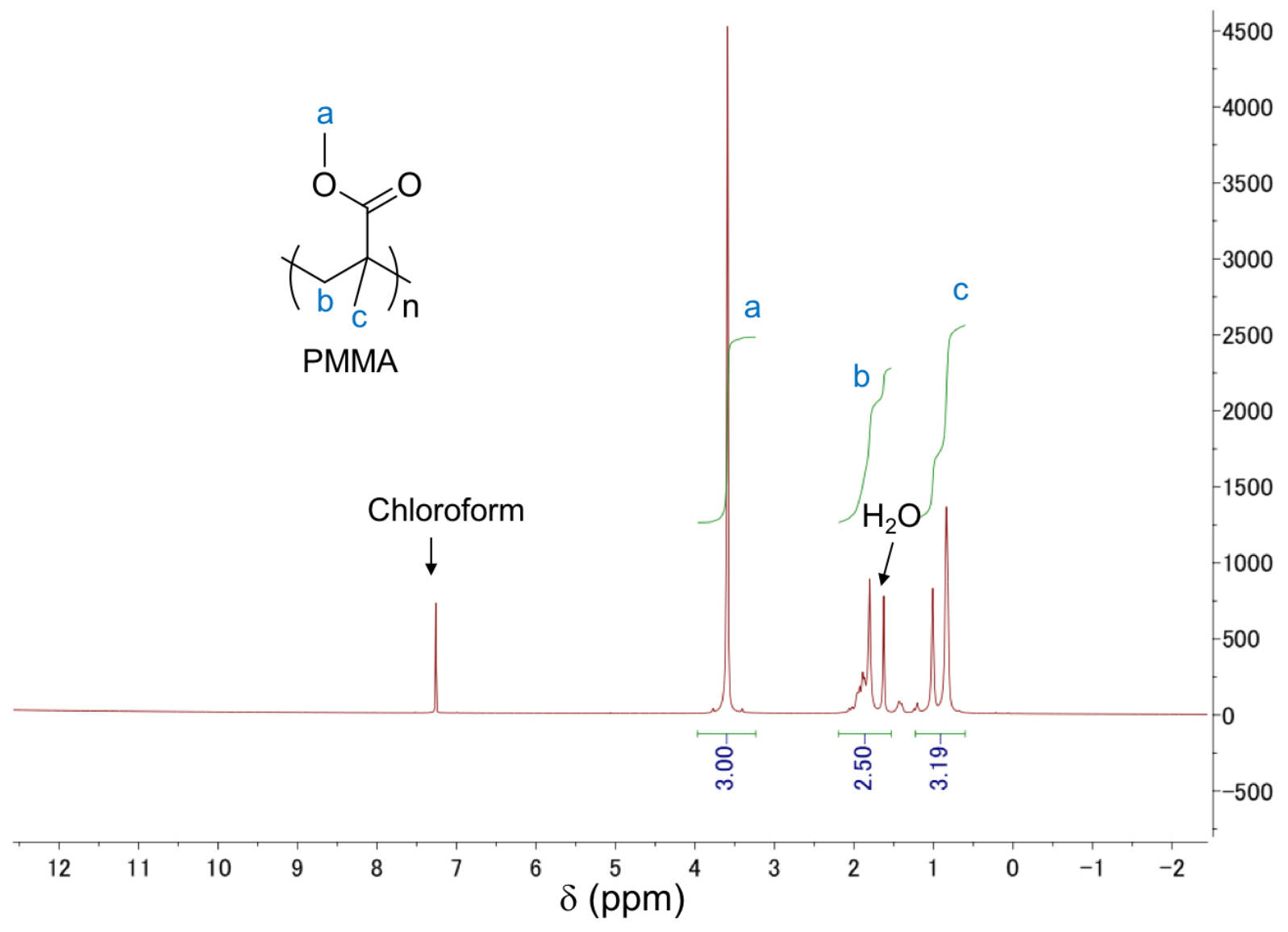

Figure S4. NMR spectra of digested ZIF-8-PMMA. 


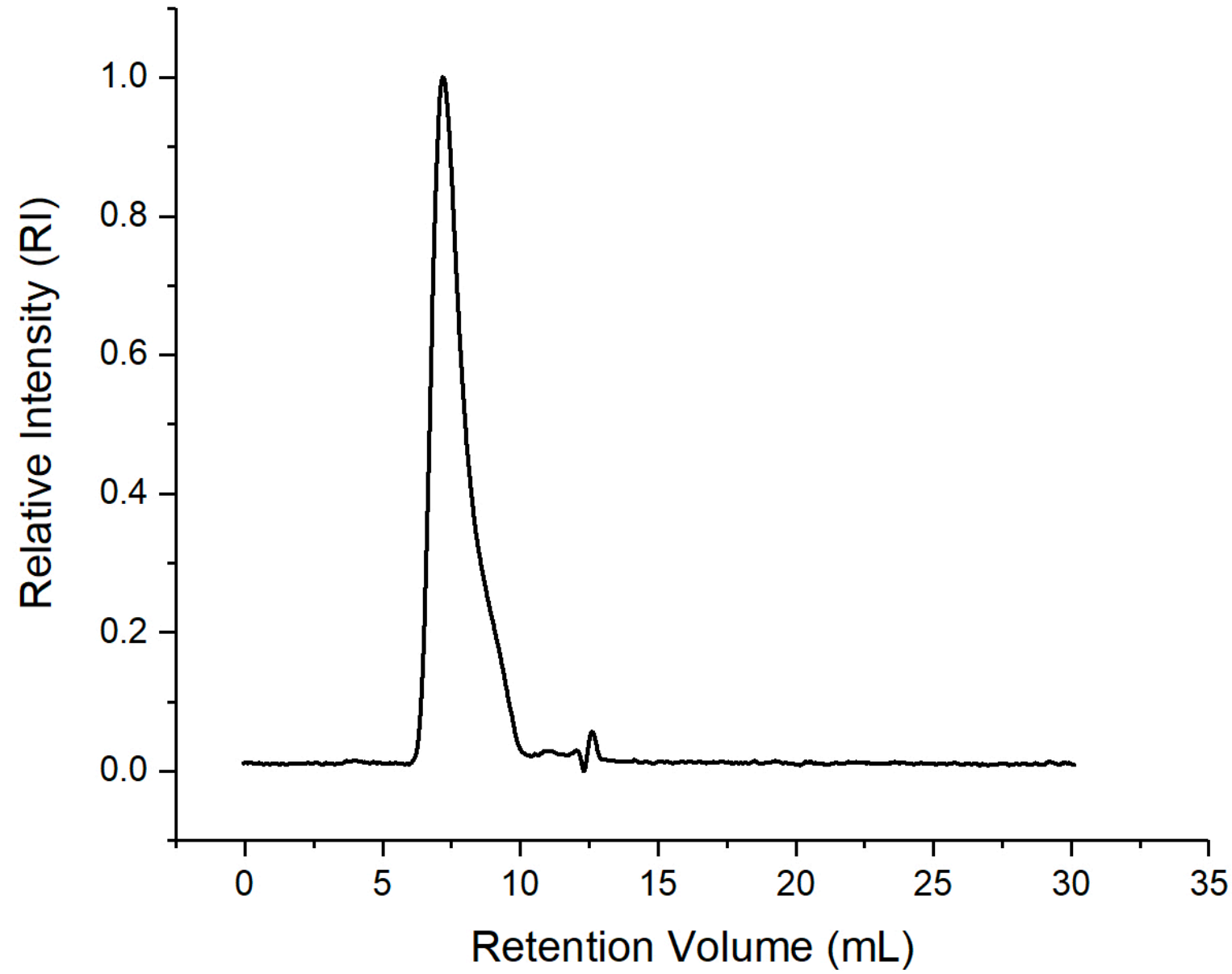

Figure S5. GPC trace of digested ZIF-8-PMMA. 


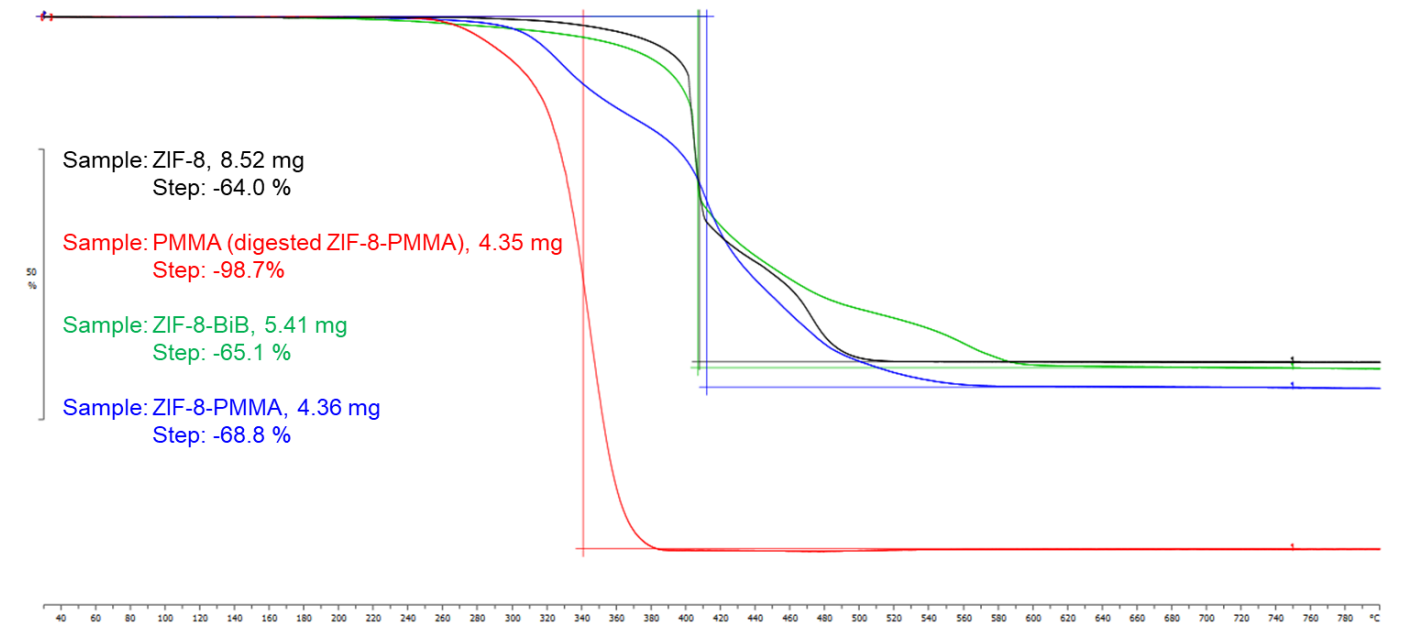

Figure S6. TGA data example for ZIF-8 (Black), PMMA (Red), ZIF-8-BiB (Green), ZIF-8PMMA (Blue). PMMA was obtained from digested ZIF-8-PMMA. 


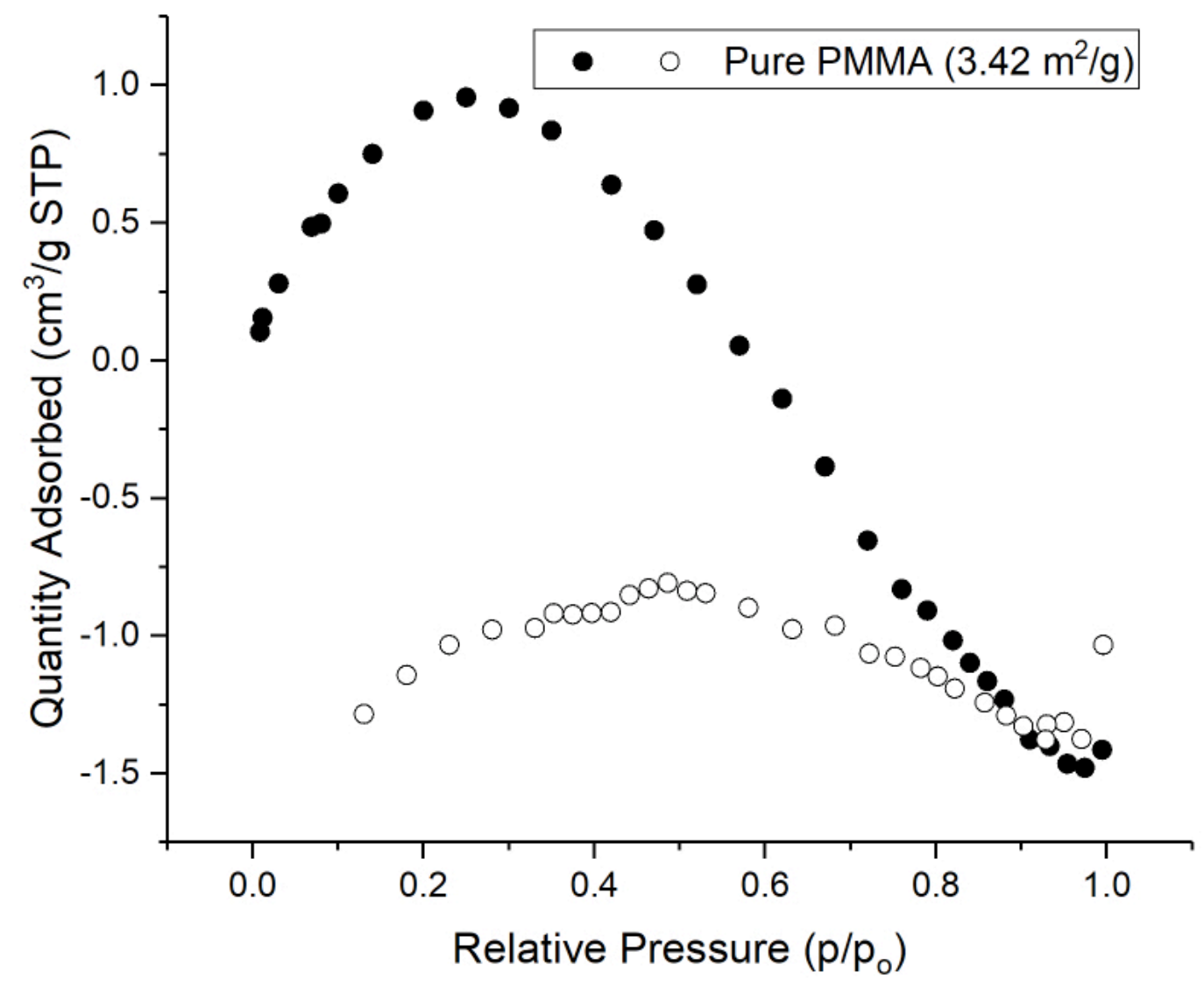

Figure S7. $\mathrm{N}_{2}$ adsorption isotherm for bulk PMMA (Aldrich, average $\mathrm{M}_{\mathrm{w}} \sim 120,000$ ). 

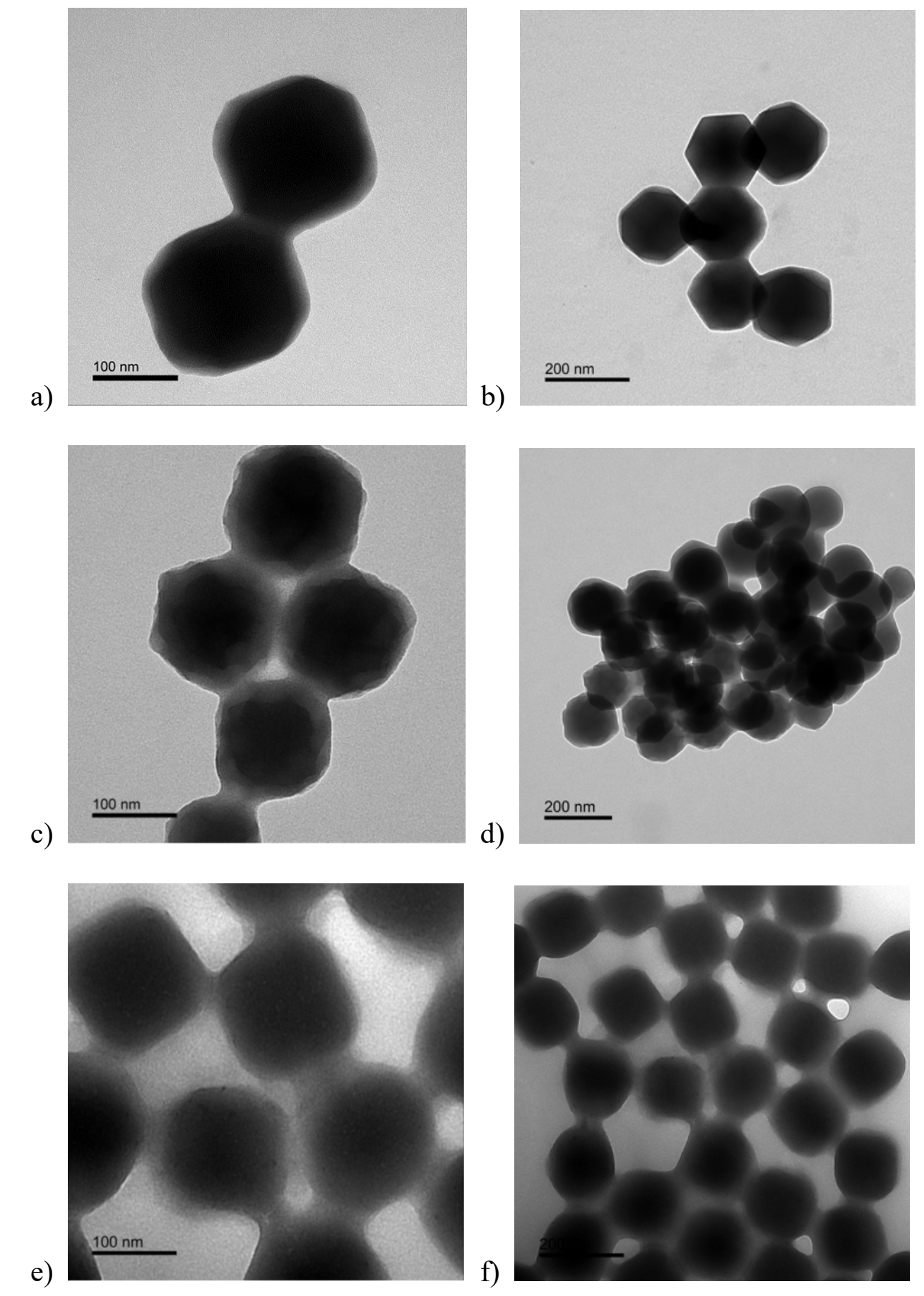

Figure S8. TEM image of particles: (a-b) ZIF-8, (c-d) ZIF-8-BiB, (e-f) ZIF-8-PMMA. Scale bars are $100 \mathrm{~nm}$ for (a), (c), (e) and $200 \mathrm{~nm}$ for (b), (d), (f). 
a)

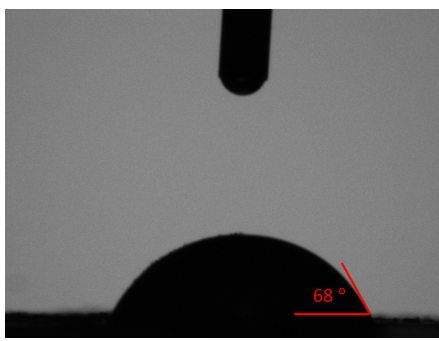

b)

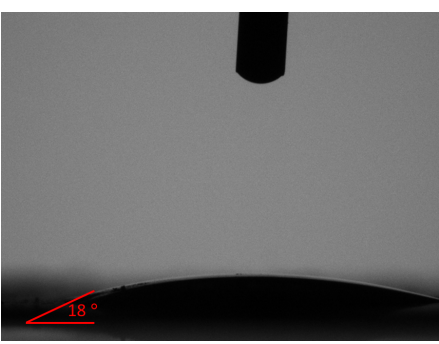

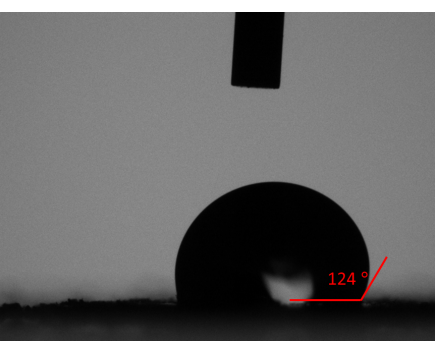

Figure S9. Contact angle measurement of particles: (a) ZIF-8, (b) ZIF-8-BiB and (c) ZIF-8PMMA.

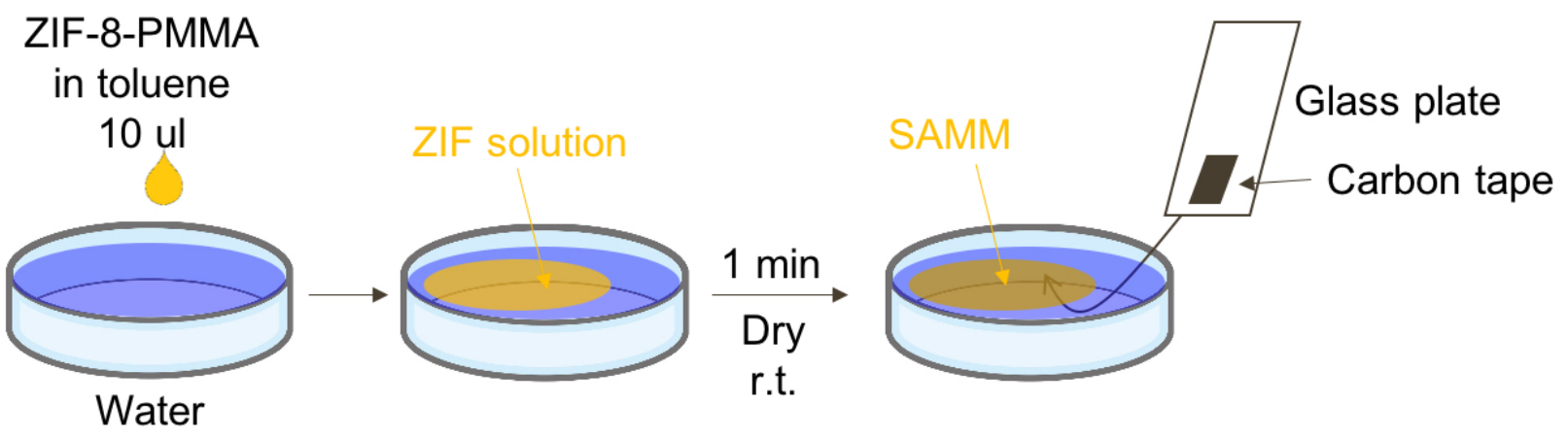

Figure S10. Procedure of evaporation-induced interfacial assembly. 
a)

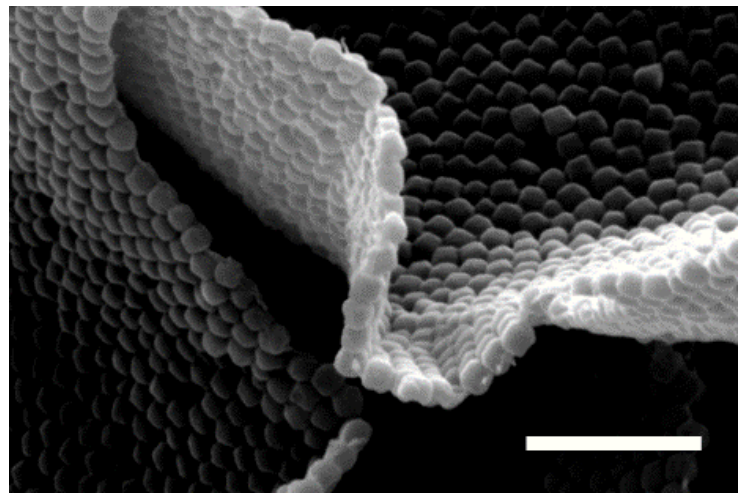

b)

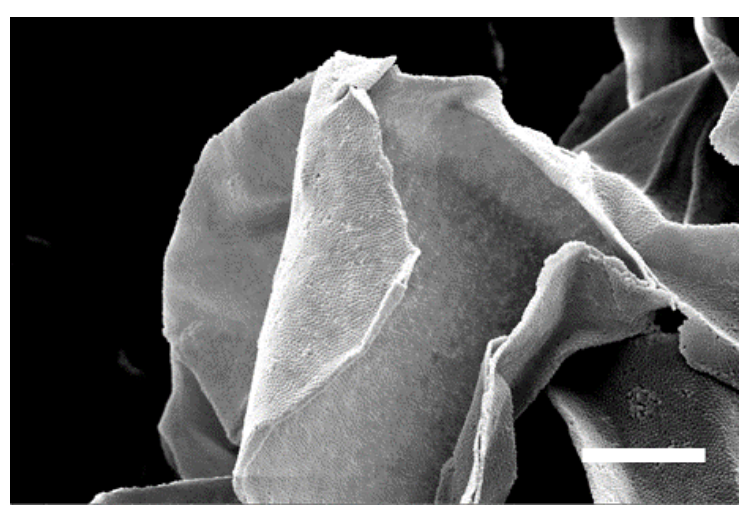

c)

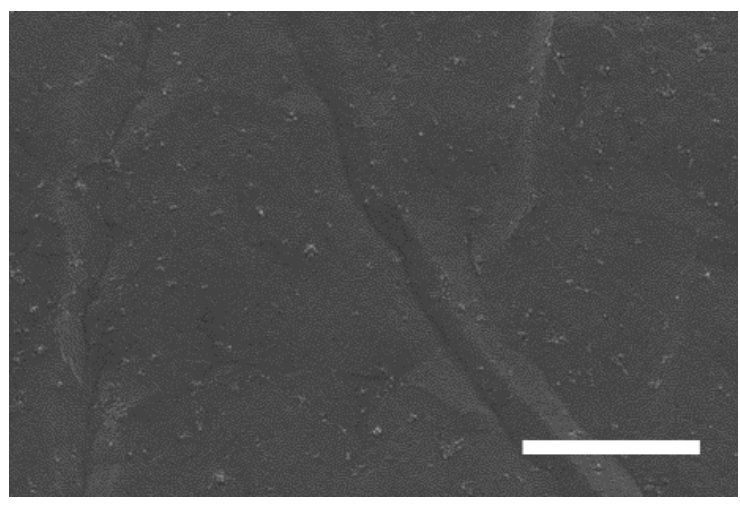

Figure S11. Other SEM image of particles obtained via the evaporation-induced interfacial assembly. (a-b) wrinkles of SAMM film: (a) Scale bar is $1 \mu \mathrm{m}$, (b) Scale bar is $5 \mu \mathrm{m}$. (c) Reduced top view of SAMM film. Scale bar is $10 \mu \mathrm{m}$. 
a)

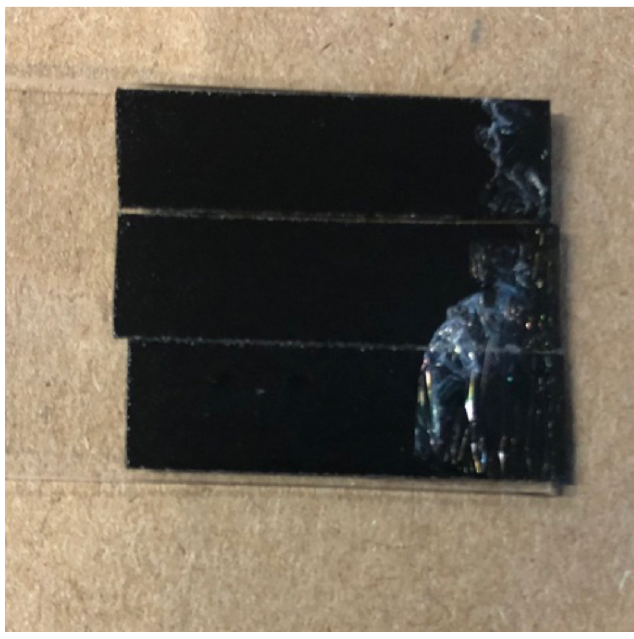

b)

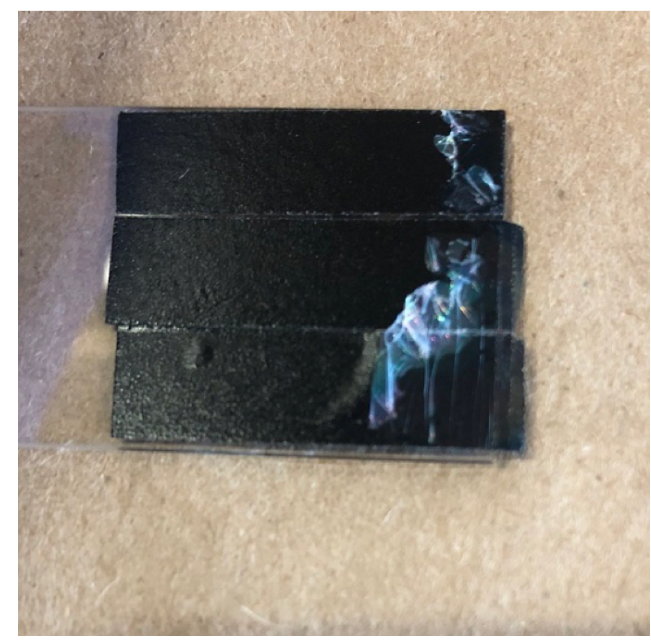

Figure S12. Optical images of SAMM film on glass plate and carbon tape: (a) as-synthesized and (b) after exposure to $\mathrm{H}_{2} \mathrm{O}$ for $2 \mathrm{~h}$.

a)

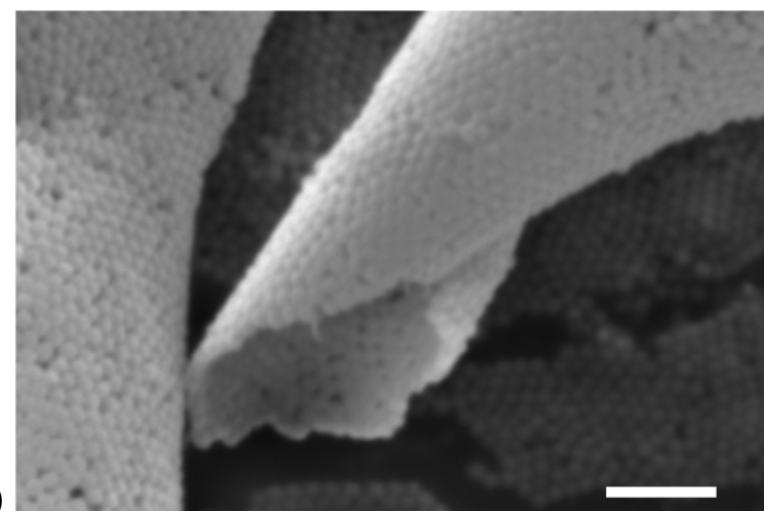

b)

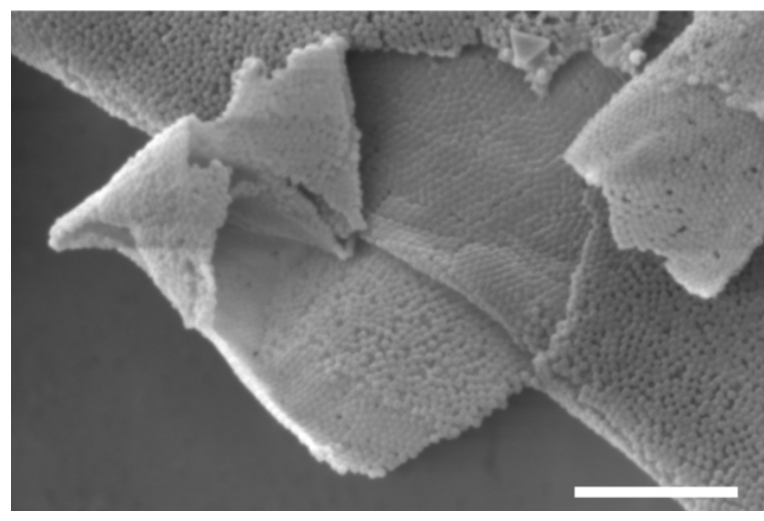

c)

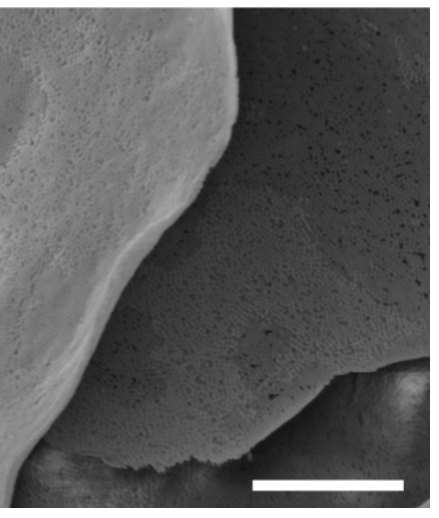

d)

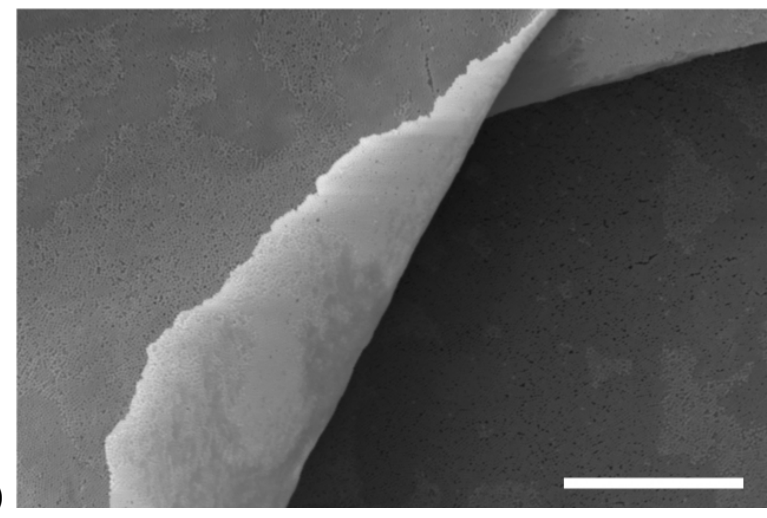

Figure S13. SEM image of SAMM films after exposure to $\mathrm{H}_{2} \mathrm{O}$ for $2 \mathrm{~h}$ at several magnifications:

(a) Scale bar is $1 \mu \mathrm{m}$, (b) $3 \mu \mathrm{m}$, (c) $5 \mu \mathrm{m}$, and (d) $10 \mu \mathrm{m}$. 
a)

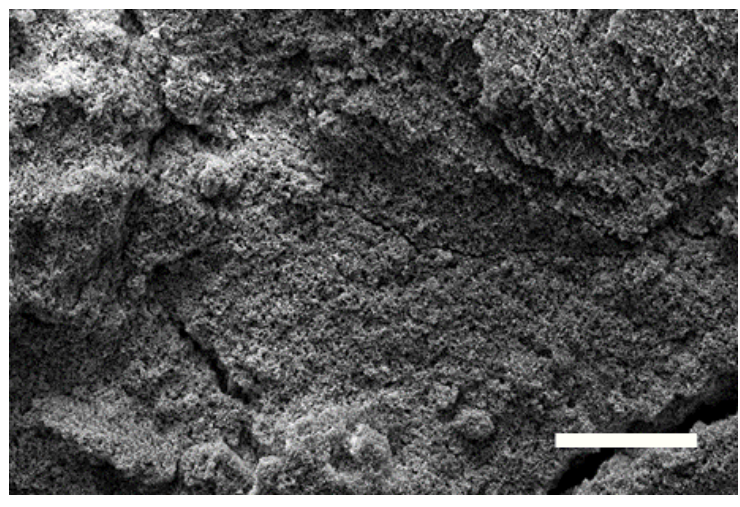

c)

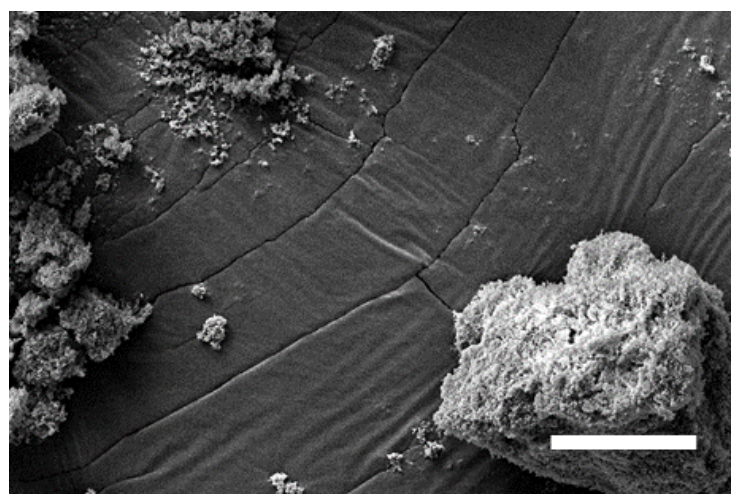

d)
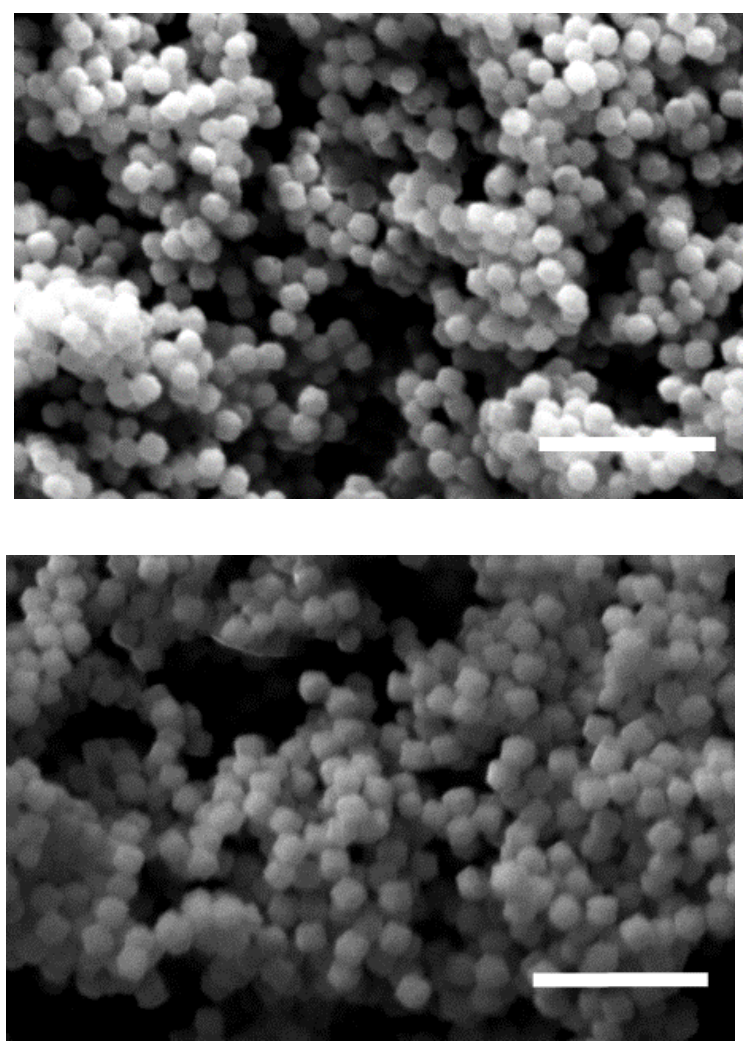

e)

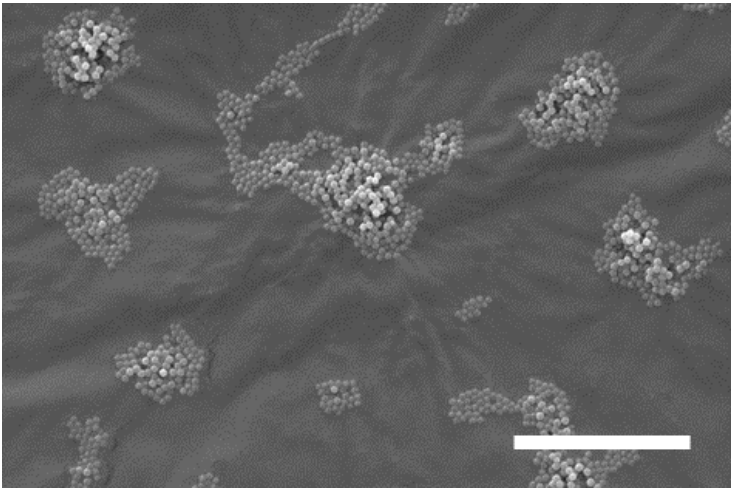

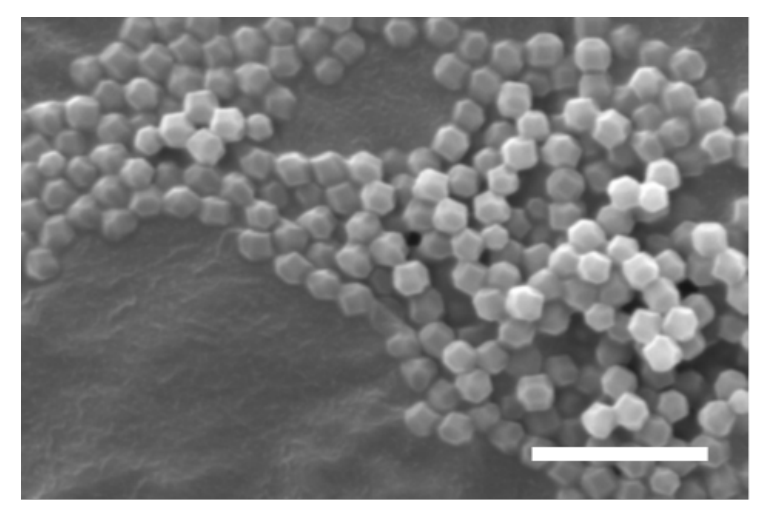

Figure S14. SEM image of particles obtained via the evaporation-induced interfacial assembly:

(a-b) ZIF-8, (c-d) ZIF-8-BiB, (e-f) physical mixture of $85 \mathrm{wt} \%$ of ZIF-8 and $15 \mathrm{wt} \%$ of PMMA polymer. Scale bars are $20 \mu \mathrm{m}$ for (a) and (c), $1 \mu \mathrm{m}$ for (b), (d), (f), $5 \mu \mathrm{m}$ for (e). 
a)

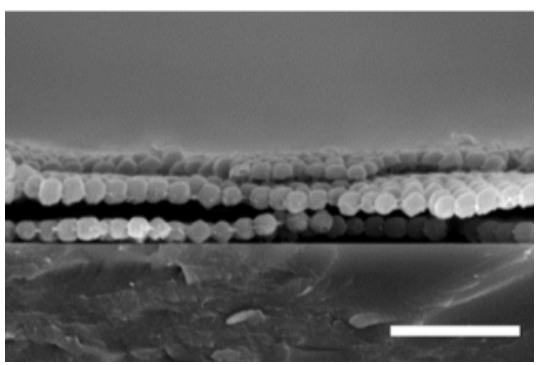

b)

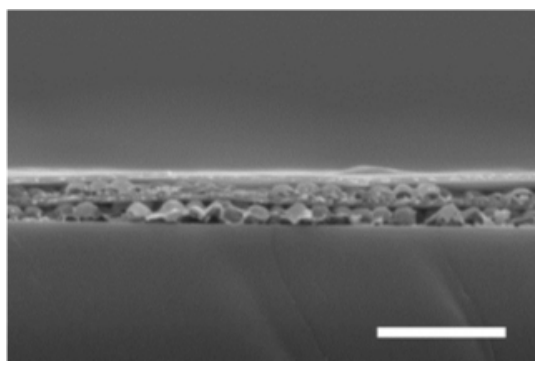

Figure S15. (a) Cross section SEM image of SAMM multi-layered film (three layers). Scale bar is $1 \mu \mathrm{m}$. (b) Cross section SEM image of multi-layered film with SAMM and PMMA thin film: Scale bar is $1 \mu \mathrm{m}$.

a)

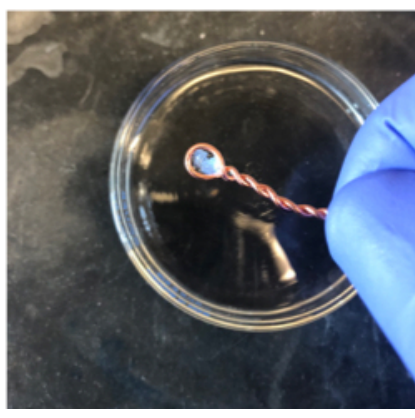

b)

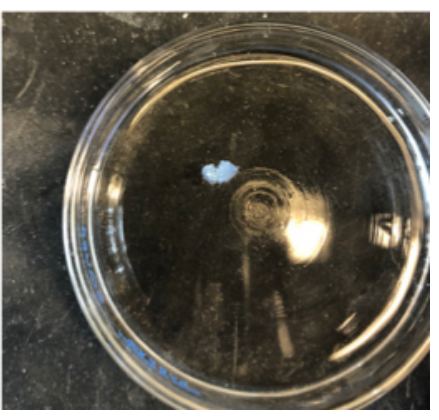

c)

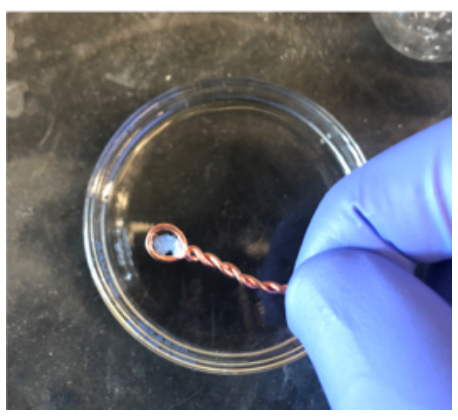

Figure S16. Optical images of SAMM multilayer film (a) as synthesized and b) soaking in $\mathrm{H}_{2} \mathrm{O}$ and (c) after exposure to $\mathrm{H}_{2} \mathrm{O}$ for $2 \mathrm{~h}$. 
Determination of conversion of the surface of PSE reaction and his-BiB density on the

\section{surface}

Average particle facet length of ZIF-8-BiB was roughly $175 \mathrm{~nm}$ as determined by SEM. The volume of each particle was calculated by (volume of a cube):

$$
(175 \mathrm{~nm})^{3}=5.36 \times 10^{6} \mathrm{~nm}^{3} / \text { particle }
$$

The length of a side of the unit cell of ZIF-8 is $1.6993 \mathrm{~nm}$ based on the literature (Gaillac, R.;

Pullumbi, P.; Coudert, F.-X., Melting of Zeolitic Imidazolate Frameworks with Different Topologies: Insight from First-Principles Molecular Dynamics. J. Phys. Chem. C., 2018, 122, 6730-6736). Therefore, the volume of the unit cell is calculated by

$$
(1.6993 \mathrm{~nm})^{3}=4.91 \mathrm{~nm}^{3} / \text { unit cell }
$$

The number of 2-methylimidazole ( $\mathrm{Im})$ in each unit cell is 24 . Therefore, the number of $\mathrm{Im}$ in each particle is calculated by

$$
\frac{5.36 \times 10^{6} \mathrm{~nm}^{3} / \text { particle } \times 24 \mathrm{Im} / \text { unit cell }}{4.91 \mathrm{~nm}^{3} / \text { unit cell }}=2.62 \times 10^{7} \mathrm{Im} / \text { particle }
$$

The mole ratio of 2-methylimidazole to his-BiB in ZIF-8-BiB is 1.94 mol\% as determined by NMR (Figure S2, this can change depending on the PSE conversion). The number of his-BiB is calculated by

$$
2.62 \times 10^{7} \mathrm{Im} / \text { particle } \times 0.0194=5.09 \times 10^{5} \text { his }-B i B / \text { particle }
$$

The surface area of each particle is given by:

$$
(175 \mathrm{~nm})^{2} \times 6=1.84 \times 10^{5} \mathrm{~nm}^{2} / \text { particle }
$$

The surface area of one face of unit cell is given by:

$$
(1.6933 \mathrm{~nm})^{2}=2.89 \mathrm{~nm}^{2} / \text { unit cell }
$$

Therefore, surface exposed 2-methylimidazole is calculated by; 


$$
\frac{1.84 \times 10^{5} \mathrm{~nm}^{2} / \text { particle } \times 24 \mathrm{Im} / \text { unit cell }}{2.89 \mathrm{~nm}^{2} / \text { unit cell }}=1.53 \times 10^{6} \mathrm{Im} / \text { particle surface }
$$

Considering that his- $\mathrm{BiB}$ is located on the surface, the mole ratio of 2-methylimidazole on the surface to his- $\mathrm{BiB}$ on the surface is calculated by;

$$
\frac{5.09 \times 10^{5} \mathrm{His}-\mathrm{BiB} / \text { particle surface }}{1.53 \times 10^{6} \mathrm{Im} / \text { particle surface }} \times 100=33 \%
$$

Therefore, the conversion of PSE on the particle surface is around $33 \%$.

In addition, the his-BiB density which is equal to the initiator density on the surface is calculated by;

$$
\frac{5.09 \times 10^{5} \mathrm{His}-\mathrm{BiB} / \text { particle }}{1.84 \times 10^{5} \mathrm{~nm}^{2} / \text { particle } \times 6}=0.45 \text { his }-\mathrm{BiB} / \mathrm{nm}^{2}
$$

